\title{
Conflicto y representación. El “tano” criminal en un sainete de Carlos Mauricio Pacheco ${ }^{1}$
}

\author{
Celia de Aldama Ordóñez ${ }^{2}$
}

Resumen. Indagar acerca del tipo de representación del inmigrante italiano en Los disfrazados (1906), pieza breve firmada por el sainetero criollo Carlos Mauricio Pacheco, constituye la principal incógnita a desvelar a lo largo de las siguientes páginas. La reflexión que en ellas se recoge centra su atención en el personaje del "tano" para tratar de especificar los rasgos con que se perfila, desde las tablas, la imagen de los nuevos actores sociales arribados al arrabal porteño desde las orillas europeas. El acercamiento al personaje del "gringo" como cuerpo ideológico será indispensable para poner de relieve los conflictos de convivencia entre inmigrantes y criollos en un horizonte político dominado por los discursos nacionalistas que criminalizan al extranjero a través de los estigmas de la enfermedad y la violencia.

Palabras clave: Carlos Mauricio Pacheco; sainete criollo; inmigración italiana; “gringos”; máscara.

\section{[en] Conflict and Representation. The criminal "tano” in Carlos Mauricio Pacheco's one-act comedy}

Abstract. This article examines the way in which the Italian immigrants are represented in Los disfrazados (1906), a one-act comedy written by Carlos Mauricio Pacheco. Our reflection focuses its attention on the character of the "tano" to specify features that create an original image of the new social actors who came from Europe. The approach to the character of the "gringo" as an ideologema is essential to highlight the conflicts of cohabitation among immigrants and criollos in a political horizon dominated by the nationalist speeches that criminalize foreigners through the stigma of disease and violence.

Keywords: Carlos Mauricio Pacheco; Sainete Criollo; Italian Immigration; “Gringos”; Masque.

Sumario. 1. Buenos Aires en un sainete. 2. Teatro de cambalache. 3. Zonzo o tigre: el disfraz de Don Pietro.

Cómo citar: De Aldama Ordoñez, C. (2018) La redención en la novelística H. A. Murena, en Revista de Anales de Literatura Hispanoamericana 47, 399-411.

1 El presente artículo ha sido creado gracias al apoyo del Ministerio de Educación, Juventud y Deporte de la República Checa y se inscribe en el proyecto IGA_FF_2018_015 (Literaturas y lenguas románicas: tradiciones, tendencias contemporáneas y nuevas perspectivas).

2 Palacký University, Olomouc. República Checa.

E-mail: c.aldama@ucm.es 


\section{Buenos Aires en un sainete}

La escritura teatral de Carlos Mauricio Pacheco (1881-1924) arranca con la apertura del nuevo siglo y, a través de ella, el joven dramaturgo participa en el bullicioso debate de ideas que recorre el campo intelectual argentino en los años de su Centenario. En la conocida como época de oro del teatro nacional, y al mismo tiempo que Florencio Sánchez, Gregorio Laferrère y Roberto Payró debutan en los circuitos artísticos porteños, Pacheco estrena sus sainetes en las principales salas de Buenos Aires y al amparo de las nuevas compañías en auge. ${ }^{3}$ Tal prolífica actividad en los albores del siglo XX, ha llevado a David Viñas a identificar a este hombre de teatro con el "paradigma del sainetero entre 1910 y 1920" (1973: 54): su figura va a representar para el teatro popular lo mismo que la de Florencio Sánchez para el sistema culto. Sin embargo, a diferencia de este, Pacheco — vinculado al submundo saineteril- ocupa un lugar de menor prestigio en la historia de la literatura nacional $\mathrm{y}$, en consecuencia, su interminable elenco de títulos, responsable de forjar un estilo genuino para el sainete criollo, permanece a la espera de un estudio que dé cuenta de sus rasgos distintivos y de los aportes renovadores que determinan la evolución del género.

Aunque el nacimiento de Pacheco se produce en Montevideo — ciudad de exilio de su progenitor-, su obra se desarrolla de manera integral en Buenos Aires. En el ambiente de modernización teatral de los primeros años del novecientos, este incansable autor de sainetes participa en la fundación de la Sociedad Argentina de Autores Dramáticos y es reconocido por sus contemporáneos como "un bohemio voluntario de elegante apariencia, que anima las veladas del Café de los Inmortales, La Armonía y El tropezón” (Pacheco 1966: 6). Si se sigue su rastro, la figura de Pacheco reaparece en múltiples escenarios, bien sea debutando como actor bajo la dirección de Ezequiel Soria, bien sea ejerciendo como periodista, en concreto como cronista teatral para el diario El País. ${ }^{4}$ Su entrada en el mundo teatral como dramaturgo se produce, en cambio, gracias a Pedro E. Pico, quien lo invita a teatralizar su relato Música criolla, publicado en la revista P.B.T. Su estreno en 1906 por la compañía de los Podestá representa el primero de una sucesión imparable de éxitos. A partir de ese momento, sus piezas ocupan un lugar central en las carteleras de la época pues son garantía para los empresarios teatrales de un éxito seguro de taquilla. De las setenta y ocho obras que escribe hasta 1924, Los

3 La recopilación bibliográfica de Marta Lena Paz permite comprobar que Carlos Mauricio Pacheco, a partir de 1905, estrena sus sainetes en los escenarios más prestigiosos de Buenos Aires —el Teatro Nacional, el Teatro Apolo y el Teatro Argentino- y que sus elencos incluyen a actores como Luis Arata o Florencio Parravicini, los más célebres dentro de los repertorios populares.

4 En su figura se delinea, al igual que en la de otros dramaturgos de la época, la del "escritor profesional”, irreconciliable con aquella del "escritor gentleman". Acerca de la profesionalización del intelectual, Altamirano y Sarlo puntualizan: "Cuando nos referimos a escritores profesionales (tanto en el Centenario como, con algunas variaciones, en las vanguardias del veinte) lo que define la cuestión no es la forma en que los escritores obtenían sus medios de vida [...]. Se trata más bien del proceso de identificación social del escritor: hombres que dejaban de ser políticos y a la vez escritores para pasar a ser escritores que, justamente en la práctica de la literatura, afirmaban su identidad social. Los escritores del Centenario le dan un impulso decisivo a un proceso que había comenzado con el modernismo: el de la diferenciación de los escritores respecto de la «buena sociedad» y el de incorporación a la capa intelectual de hombres que no pertenecían a familias oligárquicas (aparecen entonces los primeros apellidos judíos e italianos de la literatura argentina)” (1997: 214). 
disfrazados (1906), El patio de Don Simón (1908), El diablo en el conventillo (1915) y Barracas (1918), constituyen sus títulos más celebrados. ${ }^{5}$

El sainete que llega desde España a las costas argentinas lo hace en su forma primitiva, es decir, como pieza breve y reidera, sostenida sobre la comicidad de la caricatura y de los personajes estereotipados. ${ }^{6}$ Pacheco, continuador de la labor iniciada por los "primeros saineteros criollos" (Bremer 1985) —entre ellos Nemesio Trejo y Miguel Ocampo-, será el responsable de separarse de los moldes peninsulares, fijar su nueva estructura e imprimir sobre ella sus rasgos característicos. "Un trasfondo de amargura, un fuerte determinismo" alejan su modelo - en palabras de su prologuista - "del sainete español y lo acercan al futuro grotesco criollo, del que puede considerase un valioso antecedente" (Pacheco 1966: 7). ${ }^{7}$ El contexto socio-cultural en que Pacheco irrumpe con sus primeras piezas brinda las coordenadas idóneas para que se produzca tal afianzamiento: el paisaje urbano en mutación, la inquietud ante el desborde demográfico, el hacinamiento poblacional, las tensiones provocadas por la irrupción cosmopolita, la euforia del Centenario, las nuevos hábitos citadinos, el ascenso de las clases medias, la formación de un público de masas, el teatro por horas y la creciente demande del espectáculo comercial funcionan como detonantes para la suplantación de los consabidos temas y tipos por aquellos que habitan en la Babel del Plata. ${ }^{8}$

Pacheco, atento a su entorno social, opta por explorar las posibilidades que le ofrece un género menor; la tensión que ejerce sobre el corsé de la convención española le permite dar, dentro del mismo, con un cauce de expresión propia. ${ }^{9}$ Atendiendo a la exigencia general de concretar un arte nacional, los sainetes de Pacheco acogen las vicisitudes de la vida argentina que le son contemporáneas. Sus piezas, hoy leídas como documentos de archivo con un interés meramente testimonial, en la época de su estreno reprodujeron sobre las tablas situaciones que eran cotidianas en los ambientes porteños: la modorra de los cafés nocturnos, las trifulcas entre cónyuges dentro del conventillo, las tardes en el circo, la euforia y la

5 Para la sistematización y el comentario de la bibliografía completa del autor, véase Lena Paz (1963). Su recopilación crítica, que reúne los datos relativos a cada estreno, las modalidades de cada representación, los argumentos de las obras y las críticas periodísticas, supone una herramienta de gran utilidad a la hora de acercarse a un autor como Pacheco, emblemático dentro del género nacional del sainete criollo pero escamoteado por la crítica y los lectores de la segunda mitad del siglo XX.

$6 \quad$ El principal responsable en España de la renovación del género y de su estilización es Carlos Arniches (18661943), cuya obra delimita un antes y un después en el largo recorrido del sainete, preparando la transición del mismo hacia la tragedia grotesca. Para una historia del teatro breve en España, véanse Peral Vega (2000) y Huerta Calvo (2008).

7 Acerca del consciente alejamiento de Pacheco con respecto al sainete de España, Raúl Gallo transcribe las palabras del autor: "Yo no soy un sainetero; ni el mejor ni el peor. Nuestra formación social impide que destaquemos al tipo noble que ha permitido a Ramón de la Cruz y a otros bellos ingenios, crear el sainete y la figura del sainete. Yo he tomado a tipos más o menos caricaturales de nuestro conglomerado violento y los he llevado a la escena, pero tratando en todas mis obras de salvar un aspecto moral o espiritual de esa alma anónima del pueblo" (1970: 167).

8 Según Mariano Bosch, el sainete ha de considerarse como la primera genuina encarnación de la argentinidad: "la producción verdaderamente nacional, aquella en que el espíritu criollo independizado en absoluto de la influencia extranjera, se manifestaba con caracteres propios admirables era el sainete, el entremés, la petipieza, donde hasta los bailes con que terminaban, estaban lanzando efluvios de patria argentina pura” (1969: 18).

9 Para un panorama completo del origen y evolución del género y una detallada ubicación de Carlos Mauricio Pacheco en las coordenadas teatrales de su época, véanse Gallo (1970) y Pellettieri (1996 y 2008). 
ruina en el hipódromo de Lomas, el cosmopolitismo desenfrenado, las muchedumbre en el Hotel de Inmigrantes, los enredos en los cafés, los encuentros en las milongas y el imparable movimiento de los barrios que nacían a las orillas de la ciudad. A través de sus tipos, la ciudad se desdobla ante los ojos de los espectadores - muchos de ellos de origen inmigrante - que abarrotan los teatros a principios de la centuria. La urbe se instala, en pequeña escala, sobre el escenario, desde donde hablan también los recién llegados y donde los conflictos que median entre extranjeros y criollos encuentran un lugar de despliegue. Esta oposición recorre toda su obra: Pan amargo y Barracas escenifican un conflicto obrero, El Patio de Don Simón una pugna generacional entre hijos argentinos y padres inmigrantes, Los tristes una pelea entre trabajadores extranjeros y una caterva de atorrantes criollos. ${ }^{10} \mathrm{El}$ mismo Pacheco escribe al respecto:

Pocas sociedades como la nuestra ofrecen el múltiple y babilónico entrechocar de tipos y de aspectos, y en la tramitación de esta raza el compacto vivir jadeante determina curiosas modas caricaturales por la fuerza expresiva del contraste cosmopolita, tan dócil a la caricatura, desde el gesto a la fonética. Pero el espíritu es grave, es una inquietud sin alegría. Por eso el teatro de observación directa trata de equilibrar lo grotesco y lo trágico auscultando el momento social. El teatro representativo e histórico que haya dado sus puntos aún mal saboreados, participa del viejo género español denominado sainete pero está lejos de ser un remedo ni presenta verdadera afinidad por aquél. (Pellettieri 1996: 106)

\section{Teatro de cambalache}

Distintos críticos han sugerido la estrecha vinculación que existe entre el desembarco masivo de inmigrantes en el puerto de Buenos Aires y el amplio desarrollo que conoce el género del sainete en los escenarios nacionales. Pacheco, cuya inserción en el campo intelectual se produce en los años en que la república prepara los festejos de su Centenario, opta por afincarse dentro de un género, el del sainete, que, junto con al grotesco criollo, representa — según Luis Ordaz- "la expresión dramática por excelencia de la etapa inmigratoria” (1980: 414). Gracias a Pacheco —aunque también a Enrique Buttaro, Carlos R. De Paoli y Alberto Vacarezza, entre otros-, polacos, turcos, rusos, gallegos e italianos irrumpen en los escenarios criollos, instalándose en un espacio cuya tradición les es ajena; allí son también advenedizos, personajes teatrales que reproducen sobre las tablas la

10 Añade Susana Cazap: "Pacheco no solo introdujo en este sistema textual desde lo inmanente cambios importantes que lo nacionalizaron y lo apartaron del estímulo externo que significaba el sainete español, sino que desde sus metatextos persiguió la defensa del papel del dramaturgo y del género popular que producía” (Pellettieri 1996: 104). El artículo de Cazap analiza las polémicas mantenidas por Pacheco con dos agentes del campo intelectual de la época: Florencio Parravicini y Antonio Saldías. De ellas se infiere la renuncia de Pacheco al éxito fácil conseguido a través de la nota caricatural, su alejamiento de los caracteres clownescos, la defensa del carácter literario de sus piezas y su posibilidad de dialogar con el microsistema culto realista, así como de estetizar a sus personajes. 
impostura que protagonizan dentro de la urbe. ${ }^{11}$ Tal invasión de la escena explica Pacheco- quiebra el "trazo cómico" que marca la convención saineteril peninsular pues viene a traslucir la "trágica sensación de la vida inquieta y desbordada de fiebre de conquista, que agita al inmigrante básico” en el universo del conventillo porteño (1980: 421).

Luis Ordaz, en su rastreo de la complejidad del sainete criollo más allá del pintoresquismo de sus tipos y ambientes, distingue en él dos líneas mayores que se complementan: la primera y más temprana es la que conforman autores locales como Nemesio Trejo, Ezequiel Soria y García Velloso, con los que el sainete porteño se empieza a distanciar de los patrones heredados del género chico peninsular; la segunda, inaugurada por Canillita (1902) y El desalojo (1906) de Florencio Sánchez y continuada por Carlos Mauricio Pacheco, es la que determina una ulterior renovación del género, a través de la individualización de sus máscaras y estereotipos. Las petipiezas con bailes, coro y recursos zarzueleros son desplazadas por los saineteros más jóvenes, intrépidos en su exploración de los personajes y dispuestos a traspasar los límites de su mera apariencia caricaturesca. Según la lectura de Pellettieri, un sainete como el de Babilonia (1925) "excede largamente" la que fuera su aspiración fundamental de entretenimiento, al presentar una "versión polémica de los problemas del inmigrante con el medio social" (1999: 83). Los protagonistas de Discépolo se deshacen definitivamente de la manoseada máscara del cocoliche, su ser ya no se entronca con el del tipo genérico, pues en cada uno de ellos radica un conflicto de índole existencial que lo individualiza y lo distingue del resto. Pellettieri, atento a esta ruptura, esquematiza la evolución del género en tres estadios: "del viejo sistema (el sainete) al sistema nuevo (el grotesco criollo), pasando por el sainete tragicómico" (1999: 84). De cada una de las etapas, Pellettieri distingue los rasgos que las definen y nombra a sus representantes: el "sainete como pura fiesta" — el de Alberto Vacarezza - se vertebra sobre un conflicto esquemático, que suele redundar en lo sentimental, con personajes de origen inmigrante que hablan el idioma risible del cocoliche, con la finalidad de entretener a su auditorio (1999: 85); el sainete tragicómico — representado por Babilonia - que marca una superación de la dimensión festiva en favor de la reflexividad, una intensificación de la fórmula lingüística del cocoliche y una mayor contorsión de los personajes; y como última fase de tal progresión, el grotesco criollo - hallazgo de Armando Discépolo - en que los conflictos entre individuo y sociedad se encarnizan, los personajes se encogen en la angustia existencial de que son portadores y los diálogos "se adelgazan hasta convertirse en tenue confidencia” (Viñas 1973: 16). ${ }^{12}$

11 La irrupción inicial se produce dentro de los marcos del "sainete como pura fiesta” y es la que lleva a escena el conventillo verbenero, con tipos y conflictos estereotipados cuya finalidad reidera se resuelve en una especia de commedia dell'arte a la criolla.

12 Mientras Viñas (1973) confirma que escribir grotescos significa asumir un compromiso y defender una postura política, Pellettieri advierte cómo, también en las fases anteriores del sainete como "pura fiesta” y el sainete tragicómico, los personajes pueden leerse como cuerpos ideológicos. En la primera de esas fases, en la construcción paródica de la imagen del inmigrante subyacen las versiones xenófobas tan extendidas en los años de entresiglos, mientras que en el caso del sainete tragicómico de Babilonia se construyó "una imagen del inmigrante que excedía su situación, que incluía a toda la sociedad y que esa imagen se originaba, y a la vez, trasuntaba, su valoración ideológica social de la realidad sintetizada en la obra: el concepto ideologema del cambalache, del amontonamiento y de la confusión”(1999: 92). 
En ese tránsito del sainete hacia su refinamiento, Pacheco tiene un papel central pues, además de refundar sus marcas tradicionales, insiste en el trabajo estilístico y de teatralización necesarios para modelar los elementos inmediatos de la realidad social. "Todos los tipos de mis sainetes" — expresa el autor- "son sacados de la realidad pero nunca los presenté tal como los vi. Por sobre ellos puse un baño de idealismo. Busqué entre esas vidas oscuras y torpes, el rayito de sol” (Pellettieri, 1996: 106). Existe, entonces, en el dramaturgo, una clara conciencia acerca de la posibilidad de intervenir en la construcción de sus personajes, cuya variedad se incrementa a medida que el género amplía sus dominios.

Por lo que se refiere al personaje del "gringo" en el sainete, no existen estudios que hayan dado cuenta de manera minuciosa de las variantes de su estereotipización y de los elementos que participan en su construcción ideológica. ${ }^{13}$ Ante tal vacío y ante las tipologías resultantes de cada caracterización, cuya variedad no permite agruparlas aquí, este trabajo ha optado por ocuparse de Los disfrazados - la pieza más popular de Pacheco - con el propósito de examinar las representaciones del "tano" que allí confluyen. A modo de premisa, conviene recordar que el sainete ha sido tradicionalmente considerado un género idóneo para la construcción de estereotipos urbanos, cuya complejidad resulta, en distintas ocasiones, mayor de lo que cabría esperar de tales piezas breves. Ya en el primer sainete criollo, sus autores, aprovechando las estructuras paródicas y carnavalescas del género, incorporan, a través de sus tramas y personajes, visiones ideológicas a menudo disconformes con las directrices marcadas por la cultura hegemónica. No cabe duda entonces, de que, como apunta Pellettieri, "el sainete colabora en la construcción de nuestra nacionalidad durante y después de la inmigración” (2002: 206). Por lo que respecta a las obras de Pacheco, y aunque no contamos con los materiales suficientes para reconstruir su visión sobre la cuestión inmigratoria, es posible entrever en ellas una mirada conciliadora. De la mayoría de sus sainetes, se desprende un enfoque positivo de los inmigrantes que, al irrumpir en escena como sujetos industriosos y emprendedores, se sacuden las marcas caricaturales que la tradición del primer sainete les ha asignado. ${ }^{14}$ Así sucede en Los fuertes (1922), cuya acción se desarrolla en el Hotel de Inmigrantes y cuya trama exalta el espíritu de trabajo y las ansias de progreso de los recién llegados; La patria grande (1910), que escenifica a una familia de andaluces antes de partir hacia América y proyecta en su silueta el motor de la riqueza del país que los acogerá; La recova (1912), donde individuos de distinta procedencia - "la Oriental, la Turca, Don Amadeo, Doña África, el Inglés”- son retratados vendiendo su mercadería en el paseo de Julio; y La Tierra del Fuego (1922), ambientada en el patio de la Penitenciaria de las Heras y entre cuyos personajes destacan dos italianos: Stefano, por su

13 Las únicas investigaciones que hemos logrado rastrear son las de Viñas (1973) y Pellettieri (1999), ambas centradas en el caso de Discépolo. Para un estudio exhaustivo del cocoliche en el contexto del sainete, véase Blengino (2005); el autor, a través de una serie de listados de vocablos italianos que se filtran en el teatro popular argentino, demuestra la capilaridad y la riqueza de tal intromisión lingüística.

14 Este desplazamiento del grupo de personajes “débiles” al de los “fuertes” será frecuente en otros sainetes de la época, en que el inmigrante abandona su papel de personaje caricaturizado y pasa a investirse de autoridad. Algunos de los casos que hemos podido rastrear son Cuervos caseros (1905) de Luis Pascarella, La fábrica (1910) de Tito Livio Foppa, El arlequín (1910) de Otto Miguel Cione, Los inmigrantes (1921) de Filippis Novoa y El gringo Barattieri (1921) de Alberto Novión. 
bonhomía y generosidad, y el anarquista Leonardini, por la ecuanimidad de sus actos.

\section{Zonzo o tigre: el disfraz de Don Pietro}

El motivo que justifica la siguiente reflexión sobre el personaje del "tano" en el sainete Los disfrazados de Pacheco tiene que ver con la complejidad implícita en la construcción de dicha figura, de la que se desprende una valoración ideológica del entorno que disiente de aquella representada por el discurso de la dirigencia criolla. Los disfrazados (1906) — pieza de enorme circulación en la época y rescatada por la crítica moderna por el salto de renovación que le impone al género- consagra a su autor definitivamente en la escena nacional. Su estreno en el Teatro Apolo supone un éxito tan desmesurado que la obra se mantiene en cartel durante varios meses y las salas dedicadas al sainete recurren a ella como pieza de reposición durante los siguientes años. Los disfrazados marca un hito en la evolución del género pues, según la clasificación de Osvaldo Pellettieri, delinea el "modelo" del sainete tragicómico reflexivo (2002: 209), aquel que marca una superación del "sainete como pura fiesta" y experimenta una intensificación de su componente reflexiva; en este estadio, añade el investigador, la principal invención es "lo patético", que aparece en alternancia con lo cómico. ${ }^{15}$ En efecto, en este texto de Pacheco, cuya textura se ve marcada por el cruce entre las convenciones del primer sainete y la emergencia de los trazos que prefiguran su desvío hacia el grotesco criollo, hace su irrupción el contenido amargamente existencial. ${ }^{16}$ La inmigración, puntualiza Blas Raúl Gallo, resulta una factor indispensable para explicar la aparición de esta inédita cadencia: "La influencia de los inmigrantes de la baja Italia, abundante y concentrada en barrios, se manifestó con tanta agudeza que el paso del sainete al grotesco se hizo inevitable” (1980: 421). Ante estas evidencias acerca del impacto que supone la presencia del extranjero en el paisaje urbano y, en consecuencia, en el paisaje teatral —un anclaje que determina la saturación del primero y la "barroquización" 17 del segundo-, surge la necesidad de una mirada más atenta sobre el personaje del "tano", en concreto, sobre los cambios intratextuales que participan en su separación del molde genérico hasta convertirlo en un personaje individualizado.

15 Otros títulos que conforman tal paradigma son, según Pellettieri: Los políticos (1887) de Nemesio Trejo, Canillita (1902), El desalojo (1906) y Moneda Falsa (1907) de Florencio Sánchez. La caracterización que les brinda es la siguiente: “A nivel de la intriga el sainete reflexivo se puede definir como un texto de desarrollo patético con elementos melodramáticos — la coincidencia abusiva, la pareja imposible — con un desenlace esperadamente trágico que significa una pérdida total para el protagonista. El texto es modulado por la reflexión del personaje embrague” (1999: 92).

16 Para Luis Ordaz, Los disfrazados constituye el antecedente más valioso de la especie del grotesco criollo al imponer en ella "la alternancia y fusión de contrastes que Pirandello habría de llevar, algo más de una década después, a la cima del teatro contemporáneo" (1965: 16). Por su parte, apunta Pellettieri: "El pasaje del sistema viejo (el sainete) al sistema nuevo (el grotesco criollo) constituyó un largo proceso que empezó a partir de la condición reflexiva del sainete de Carlos Mauricio Pacheco” y que es continuada por Discépolo en colaboración con Folco y de Rosa en El movimiento continuo y Mustafá (2002: 458).

17 Es preciso recordar aquí las palabras de David Viñas, según las cuales "el grotesco -en tanto flexión o distorsión dificultosa y ornamental- puede interpretarse como el «barroco del sainete»: como queja, como agresión, como infracción del «equilibrio» de la regla oficial” (1973: 89). 
Si bien críticos como Pellettieri, Ordaz y Viñas han resaltado la importancia de esta pieza dentro del contexto teatral argentino, ninguno de ellos ha ahondado en la dialéctica que en ella se establece entre inmigración y enmascaramiento; este aspecto, en nuestra opinión, forma parte del debate de ideas propio de la década en que se inscribe y resulta determinante para el inminente desarrollo del canon del grotesco criollo - donde la máscara esconde casi sin excepción el rostro de sus personajes-.$^{18}$ En Los disfrazados, un inmigrante italiano de nombre Don Pietro ocupa el centro de una trama que ilumina, a través de un juego de disimulos y disfraces, las tensiones que definen sus vivencias en la Argentina de principios de siglo. El sainete, al hilvanar texto y contexto, no solo se convierte en espejo de un mundo marcado por el conflicto, sino que participa activamente en la construcción de su horizonte ideológico. La idea de fondo que allí cobra forma tiene que ver con una sociedad travestida, donde la disimulación se impone como mecanismo de defensa, dentro y fuera del mundo del conventillo. Los discursos de los sectores dirigentes acerca de los extranjeros — primero construidos sobre un prisma idealizador, después criminalizante- han terminado por afantasmarlo; la identidad del "gringo" — un individuo de por sí desorientado por su doble pertenencia — se vuelve aún más difusa, quedando su imagen pública expuesta a los intereses de repoblamiento o de argentinización del país que los acoge. Esa posición intermedia, marcada por el conflicto y la incertidumbre, es reproducida en el interior del espacio del sainete, a partir del cual Borges intuye los puntos de contacto entre discurso teatral y discurso ideológico:

En el sainete nacional, los tipos del gallego y el gringo son un mero reverso paródico de los criollos. No son malvados, lo cual importaría una dignidad; son irrisorios, momentáneos, nadie. Se agitan vanamente: la seriedad de morir les está negada. Esta fantasmidad corresponde a las seguridades erróneas de nuestro pueblo con tosca precisión. Eso para el pueblo es el extranjero: un sujeto imperdonable, equivocado y bastante irreal. (Vacarezza 1993: 32)

El dramatis personae de la pieza que aquí se estudia nos sitúa frente a un amplio espectro de personajes, varios de cuyos nombres remiten al lector al universo de la "gringada": Don Pietro, Malatesta, Pelagatti y Cocoliche. La acción del sainete, que se desarrolla en un único acto, tiene lugar en "Buenos Aires, una tarde de carnaval”. La acotación inicial vierte una mirada sobre el entorno espacial de la que se desprende una actitud autoral de deliberada estilización:

Patio de un inquilinato. [...] No es el conventillo porteño sucio y complicado. Es un patio donde el autor toma sus apuntes de vida popular sin necesidad de taparse las narices. Hay en el ambiente cierto aseo, cierta limpia alegría de día de fiesta, que no se encuentra en las oscuras vecindades cosmopolitas. No es, pues, el conventillo propiamente. Son unos cuantos tipos que en la tarde carnavalesca mueven ante los ruidos cómicos de la calle, el respectivo cascabel interno. (1966: 13)

18 Claudia Káiser escribe al respecto: "Si este teatro (el grotesco criollo) reconoce en el ser humano una dimensión interior, también reconoce que está preso bajo una máscara; ahogado por la postura que la necesidad de vivir y funcionar dentro de la sociedad le obliga a asumir” (1977: 57). 
Aparentemente, la armonía reina en el ambiente, donde pululan —con ademán despreocupado - un gran número de personajes: gauchos, vecinos, curiosos y cocoliches en torno a un gaucho cantor. En principio, los elementos que aparecen en escena parecen remitir a los recursos tradicionales del "sainete como pura fiesta”: el ambiente externo del patio del conventillo, la música del coro, la animación y las bromas de los tipos allí congregados, su caricaturización, etc. Los primeros en entrar en escena son tres paisanos -Paisano $1^{\circ}$, Paisano $2^{\circ}$ y Paisano $3^{\circ}$ - seguidos de un Cocoliche. Este intenta — “colocándose en el centro de la escena” y con "voz aflautada", según reza la acotación - continuar la payada de los anteriores con los siguientes versos: "Arroz con leche / Me quiere casar / Con una muchachita... / iqui sparanza!” (15). Ante la torpeza en la versificación y el afeminamiento de su voz, los gauchos viriles lo interrumpen con los gritos: “iVivan los hijos de la pampa!” (15). ${ }^{19}$ Se traza entonces una primera zona de exclusión: Cocoliche, al fracasar como payador, queda fuera del espacio simbólico de la fiesta ocupado por los criollos. La comicidad provocada por sus versos sin rima cobra una mayor proyección pues el ninguneo que sufre por parte del resto del grupo prefigura el violento devenir de los acontecimientos que siguen. ${ }^{20}$ Otro episodio de fracaso comunicativo - agravado por un final a palos - es el que protagoniza el "gringo" Pelagatti, que entre en escena disfrazado de rey, escoltado por sus condes - “vestidos ridículamente de pluma, capa y espada”- y hablando en cocoliche:

Pelagatti- Tenese que vire, que É cuestione re familia. ¡Un prime mío ese conde n'Italia!

HILARIO- ¿Se esconde en Italia?

PelagatTI- Cuestione re familia. (28)

El malentendido entre Pelagatti e Hilario reincide en el progresivo parcelamiento de los individuos que habitan el conventillo, cada vez más separados entre sí por las barreras dialectales. En este caso, la marginación se explicita a través de una trifulca en que un grupo de gauchos hace pedazos los trajes de los condes y destrona al rey "gringo" del carnaval.

Entre todos los personajes, Don Andrés ocupa un lugar relevante por ser el personaje embrague, es decir, el portador de la tesis del autor y aquel que, por tanto, conduce las líneas de reflexión. Para Don Andrés, el carnaval es "una pavada" porque "todos vivimos disfrazados" (19), en "un mundo de locos y

19 Jorge Salessi recuerda que, frente a la cultivada masculinidad del gaucho, ciertas prácticas discursivas de principios de siglo asocian la figura del invertido a las legiones mediterráneas: "italianos, modelos o seductores, eran en este discurso un origen del mal degenerador y extranjero que llegaba, invadía, como una enfermedad y como una fuerza política que, de no ser controlada en las instituciones regeneradoras argentinas, podía transformarse en una patología social y cultural” (1995: 276).

20 Sobre la construcción del personaje del Cocoliche, escribe Blengino: “La imperfección del lenguaje del inmigrante (núcleo humorístico del sainete) tienen su correspondencia cómica en el comportamiento inadecuado del inmigrante, y por tanto al que habla cocoliche, caricatura de un lenguaje, le corresponde un personaje que es la caricatura de un personaje normal” (2007: 124). 
encaretados” (17). ${ }^{21}$ La otra función desempeñada por Don Andrés es la de ayudante de Don Pietro, personaje de refinada caracterización, cuya actitud en escena denota una aparente serenidad y ensimismamiento: "sentado frente a la puerta, con dolorosa indiferencia, apoya la barba en la palma de la mano y fuma en su pipa” (15). En medio de la algazara general, el “tano” permanece silencioso, imperturbable ante el escándalo que llega de la calle y las increpaciones de los vecinos, que lo toman por loco y por cornudo: "Está completamente azonzao. Mientras él se lo pasa contemplando su pipa, la mujer anda de farra con el otro", explica Malatesta (20). Sus únicas palabras “Miro l’humo...”, repetidas mecánicamente, contrastan, tal y como percibe Rosalía, con el parloteo de Malatesta "que no hace más que hablar..." (18). Este último, irrumpe en escena "haraganeando y cantando": "Hijo del pueblo te oprimen cadenas. Esta injusticia no puede seguir" (18). Su conducta se corresponde con la del atorrante pues, aunque propaga —sin éxito- el mensaje libertario entre los mensajes del conventillo, la vagancia es su característica predominante: "Yo prefiero no hacer nada... ¡Cuestión de ideas!” (19). La sorpresa del espectador se produce cuando este personaje con nombre italiano revela su identidad: se trata de un joven proletario criollo, empleado en el taller de Chinchino, de temperamento inofensivo, amante de las letras y cuyo nombre real es el de Correa. ${ }^{22}$ Este efecto inesperado pareciera cuestionar una asociación propagada por las élites criollas en una década marcada por los festejos del Centenario y por la convulsión social: aquella que construye un nexo de inmanencia entre la figura del extranjero y ciertos patrones científicos de peligrosidad, convirtiendo al recién llegado en sujeto criminal y violento agente del fanatismo político. ${ }^{23}$

Entre los últimos parlamentos de este personaje de ideas libertarias, es preciso resaltar aquí el que apunta a la simulación como proceder constante en el mundo del arrabal: "Yo me puso a riflesionar. ¿Sabes? Como no tengo nada que hacer... Y he pensao que es cierto, que a cada rato nos disfrazamos porque andamos fingiendo cosas” (34). De manera que, la caída de la máscara de Don Pietro se produce tras varios episodios de naturaleza conflictual —la anagnórisis de Malatesta, el destronamiento de Pelagatti y la marginación de Cocoliche- a través de los que se revela la problemática identidad de sus vecinos. Don Pietro, que en principio no participa en la mascarada general, encubre más que ninguno su auténtico rostro: su disfraz es, entre todos, el más invisible, quizás por estar su urdimbre ceñida al cuerpo que lo viste. ${ }^{24}$

21 Se trata de idea predominante en los sainetes de Defilippis Novoa. Para un estudio de la máscara en la pieza He visto a Dios, véase De Aldama Ordóñez (2014).

22 En la época, el nombre de Malatesta, además de ser reconocido como italiano, es identificado inmediatamente con el de uno de los principales difusores y propagandistas de la causa anarquista en Buenos Aires, Enrico Malatesta.

23 Si en un primer momento, criminalistas como Cornelio Moyano Gacitúa en sus Notas de filosofía penal (1894) e higienistas como Francisco de Veyga en Anarquismo y anarquistas (1897) advierten sobre los focos de infección anarquista y sobre su naturaleza “monstruosa” en los años de fin de siglo, el modelo de criminalización adquiere un estatuto legal a través de dos medidas legislativas, la Ley de Residencia en 1902 y la Ley de Defensa Social en 1910. La Ley de Residencia constituye el primer intento legislativo para dotar a la República Argentina de un sistema preventivo en defensa de "los nuevos enemigos del orden social” (Cané, 1899: 5).

24 Según Raúl Gallo, “la ciudad cosmopolita, el torrente inmigratorio, siempre renovado” impiden a Pacheco trabajar con arquetipos: "La caricatura del inmigrante, la falacia del malevaje, la esterilidad del guapismo 
Mire come me tratan la quente. [...] Todos sa rien e me miran co'l desprecio porque yo no grido, perque miro l'humo siempre. E soy un povero disgraziato que non tengo fuerza per gridar come un leone [...] E que non puedo ne trabajar ne vivir perque tengo cá dentro la tormenta... Osté vería, allá in l’imigraciún, cuando que venimo del mío paese... Entonces sí, era l’idea del trabaco e de la fortuna. E yo tenía la fuerza per mové la tierra... ¡A Ahora non vargo in pito! ¡No siento mase come ante la volontá” (23).

Es a lo largo de este parlamento cuando se produce la caída de la máscara. Al fracturarse el molde que lo contenía, emerge el llanto amargo: el dolor ligado a la condición de inmigrante, la ruina del presente, la llegada de la vejez y la merma de las fuerzas, las burlas y el escarnio de la comunidad. Tras la catarsis, Don Pietro lleva a cabo el crimen pasional y asesina, ante el asombro de los vecinos y los espectadores, a su principale contrincante, el amante de su mujer. Al final del sainete, aparece en escena el verdadero Don Pietro - “el tigre disfrazado" (42) y, junto a él, cobra relieve el auténtico conventillo, un universo de rivalidades y antagonismos que reproduce en miniatura al conjunto de la sociedad argentina. En su interior, el "gringo" Don Pietro representa el paradigma del disfrazado: con la máscara, el protagonista burlado congela su rostro, fijada su expresión en un único plano inmóvil; sin ella, se quiebra la tipificación, quedando invalidado el falso estereotipo de zonzo y cornudo. El personaje doliente emerge, entonces, con una sacudida que no puede no ser violenta: son los zarpazos de un "gringo infeliz" en actitud defensiva ante los vecinos que lo azuzan. Don Pietro, el que llegara a América como hombre emprendedor, ha desarrollado un instinto criminal, provocado, según parece apuntar Pacheco, por el contexto hostil que le depara la vida en el nuevo continente. La miseria, el hacinamiento y la purga racial son identificados como los factores sociales que explican tal degeneración, ensombreciendo la legitimidad de los patrones de criminalizantes y patologizantes que manejan las élites letradas: en este (con)texto, el acto de barbarie es precedido por un afán civilizador. Así, a partir del género menor del sainete, y a través de una perspectiva que se adentra en las causas sociales en detrimento de las explicaciones esencialistas, Pacheco cuestiona los estereotipos fijados por una oligarquía en decadencia que busca, en vano, excluir del cuerpo social a los "otros", los argentinos nuevos que lo habitan. Para ello imagina a un personaje enigmático, burlado por los vecinos del arrabal y ubicado en un entorno de falsas apariencias que parecieran reproducir la desconfianza instaurada entre "tanos" y criollos. El final trágico de la trama ratifica el conflicto que acompaña el penoso arraigo del nuevo habitante del país, aquel en que vuelven a confundirse dos estereotipos de larga trayectoria en la tradición argentina, el de la civilización y el de la barbarie. ${ }^{25}$

Como último apunte antes de cerrar esta reflexión acerca de los inmigrantes italianos que pueblan la pieza de Pacheco, señalaré cómo la puesta en escena de sus

arrabalero, enmascaran el rostro doloroso de una verdad miserable que crece incesante junto al desnivel de las clases" (1970: 170).

25 Según la perspectiva de Raúl Gallo, el dramaturgo “comprende que la suerte del gringo está irremisiblemente ligada a la del nativo. El conflicto entre ambos, si bien real, será, por lo tanto, transitorio” (1979:170). 
conflictos se sostiene sobre un entramado discursivo de singular densidad. El espesor ideológico que distingue la caracterización de estos "tanos” responde a la intención del dramaturgo de problematizar los estereotipos discriminatorios que la clase dirigente de la Argentina del Centenario impone a los recién llegados. Desde las tablas, nombres como el de Pacheco, aunque también el de Roberto J. Payró o Armando Discépolo, contrarrestan las prácticas discursivas que, en las últimas décadas y desde múltiples escenarios, han forjado un modelo excluyente de nación basado en la contraposición del neocriollo del litoral frente al gaucho y al argentino del interior. El anclaje de un personaje tan controvertido como Don Pietro colabora a inaugurar en el imaginario teatral de la época un espacio de disensión, en cuyo seno se impugna la representación del "gringo" como sujeto criminal propia de la narrativa naturalista y respaldada también, en los años de entresiglos, por conspicuos representantes de la cultura científica. El trágico final de Los disfrazados vuelve inoperantes las nociones esencialistas que hacen del extranjero un delincuente nato al mismo tiempo que bosqueja una clara advertencia: la enajenación del inmigrante no puede atribuirse a su supuesta naturaleza tarada sino que se explica a partir del medio hostil que le impone la vida en el conventillo. El cuerpo teatral del gringo queda así convertido en lugar de arraigo para las polémicas y los discursos en pugna fuera de las tablas. Si Eugenio Cambaceres desde la narrativa, Cornelio Moyano Gacitúa desde la criminología o José María Ramos Mejías desde el Departamento Nacional de Higiene afinan la correlación entre el inmigrante y el homo criminalis, también Pacheco —aunque en dirección contraria - participa en ese proceso de delineamiento y diagnóstico. Los "tanos" de sus sainetes funcionan entonces como ideologemas que, liberados de los moldes genéricos criminalizantes y patologizantes, despliegan una resistencia frente a la cadena de estereotipos y cuadros clínicos oficiales que justifican las medidas de exclusión defendidas por las élites argentinas. Es así cómo, en palabras de Herminia Petruzzi, "por medio del sainete y la comedia de costumbre, el extranjero va adquiriendo carta de ciudadanía en esta sociedad” (1981: 35).

\section{Referencias bibliográficas}

Altamirano, Carlos y Beatriz Sarlo, "La Argentina del Centenario: campo intelectual, vida literaria y temas ideológicos”, en Ensayos Argentinos. De Sarmiento a la Vanguardia. Argentina: Ariel, 1997.

Blengino, Vanni. La Babele nella "Pampa”. L'emigrante italiano nell'immaginario argentino”. Reggio Emilia: Diabasis, 2005.

-Más allá del océano: un proyecto de identidad: los inmigrantes italianos en la Argentina. Buenos Aires: Siglo Veintiuno, 2007.

Bosch, Mariano. Historia de los orígenes del teatro nacional argentino y la época de Pablo Podestá. Buenos Aires: Ediciones Solar, 1969.

Bremer, Thomas y Eva Golluscio de Montoya, "Nemesio Trejo y los primeros saineteros criollos rioplatenses: proyecto de teatro nacional y programa de gobierno radical". Giessen. 1985.

Cané, Miguel. Expulsión de extranjeros. Apuntes. Buenos Aires: Sarrailh, 1899. 
De Aldama Ordóñez, Celia, "Entre burlas y veras: lo sobrenatural como máscara del cocoliche argentino", en Sobrenatural, fantástico y Metarreal. La perspectiva de América Latina. España: Biblioteca Nueva, 2014.

Gacitúa Moyano, Cornelio. Notas de filosofía penal. Sobre el anarquismo. Córdoba: La Patria, 1894.

Gallo, Blas Raúl. Historia del sainete nacional. Buenos Aires: Buenos Aires Leyendo, 1970.

Huerta Calvo, Javier (dir.). Historia del teatro breve en España. Madrid: Iberoamericana, 2008.

Káiser, Claudia. El grotesco criollo. La Habana: Casa de las Américas, 1977.

Lena Paz, Marta. Bibliografía crítica de Carlos Mauricio Pacheco. Aporte para un estudio. Buenos Aires: Fondo Nacional de las Artes, 1963.

Ordaz, Luis. Breve historia del teatro argentino. El grotesco criollo. Buenos Aires: Editorial Universitaria de Buenos Aires, 1965.

— “Armando Discépolo o el «grotesco criollo»”, en Historia de la Literatura Argentina. Buenos Aires: Centro Editor de América Latina, 1980.

Pacheco, Carlos Mauricio. Los disfrazados y otros sainetes. Buenos Aires: Editorial Universitaria, 1966.

Pellettieri, Osvaldo. El teatro y sus claves. Estudios sobre teatro argentino $e$ iberoamericano. Buenos Aires: Galerna, 1996.

—Inmigración italiana y teatro argentino. Galerna: Instituto Italiano de Cultura, 1999.

-Historia del teatro argentino en Buenos Aires. La emancipación cultural (1884-1930). Buenos Aires: Galerna, 2002.

—El sainete y el grotesco criollo: del autor al actor. Buenos Aires: Galerna, 2008.

Peral Vega, Emilio Javier. Formas del Teatro Breve español en el siglo XX (1892-1939). Madrid: Fundación universitaria española, 2000.

Petruzzi de Díaz, Herminia (dir.). Comedias y Sainetes Argentinos. Antología. Buenos Aires: Ediciones Colihue, 1981.

Salessi, Jorge. Médicos, maleantes y maricas. Higiene, criminología, homosexualidad en la construcción de la nación Argentina (Buenos Aires: 1871-1914). Rosario: Beatriz Viterbo Editora, 1995.

Vacarezza, Alberto. Teatro. Ed. y estudio prel. de Osvaldo Pellettieri. Buenos Aires: Corregidor, 1993.

Veyga, Francisco. Degeneración y degenerados. Miseria, vicio y delito. Buenos Aires: El Ateneo, 1938.

Viñas, David. Grotesco, inmigración y fracaso: Armando Discépolo. Buenos Aires: Ediciones Corregidor, 1973. 